OPEN ACCESS

Edited by:

Xiaohui Fan,

Zhejiang University, China

Reviewed by:

Shi-Jun Yue,

Shaanxi University of Chinese

Medicine, China

Xiang $L i$,

Hangzhou Medical College, China

*Correspondence:

Zhao-Ying Liu

liu_zhaoying@hunau.edu.cn orcid.org/0000-0002-9050-2287

these authors have contributed equally to this work and share first authorship

Specialty section:

This article was submitted to

Veterinary Pharmacology and Toxicology,

a section of the journal

Frontiers in Veterinary Science

Received: 02 February 2021

Accepted: 13 April 2021

Published: 26 May 2021

Citation:

Huang $C-Y$, Huang $Y-J$, Zhang $Z-Y$, Liu Y-S and Liu Z-Y (2021) Metabolism and Tissue Distribution of Chelerythrine and Effects of Macleaya Cordata Extracts on Liver $N A D(P) H$ Quinone Oxidoreductase. Front. Vet. Sci. 8:659771.

doi: 10.3389/fvets.2021.659771

\section{Metabolism and Tissue Distribution of Chelerythrine and Effects of Macleaya Cordata Extracts on Liver NAD(P)H Quinone Oxidoreductase}

\author{
Chong-Yin Huang ${ }^{1,2 t}$, Ya-Jun Huang ${ }^{1,3+}$, Zhuo-Yi Zhang ${ }^{1,4}$, Yi-Song Liu ${ }^{1}$ and \\ Zhao-Ying Liu ${ }^{1,2 *}$
}

${ }^{1}$ College of Veterinary Medicine, Hunan Agricultural University, Changsha, China, ${ }^{2}$ Hunan Engineering Technology Research Center of Veterinary Drugs, Hunan Agricultural University, Changsha, China, ${ }^{3}$ Hunan Prima Drug Research Center Co., Ltd., Changsha, China, ${ }^{4}$ Yiyang Vocational and Technical College, Yiyang, China

Background: Macleaya cordata (Willd.) (Papaveraceae) is listed as a feed additive in animal production by the European Food Authority.

Methods: The metabolites of chelerythrine in rats were measured in vitro and in vivo by rapid and accurate high-performance liquid chromatography/quadrupole-time-of-flight mass spectrometry (HPLC/QqTOF-MS). The structures of CHE metabolites were elucidated by comparing their changes in accurate molecular masses and fragment ions with those of parent ion or metabolite. The metabolic enzymes that were involved in chelerythrine reduction were investigated using an inhibition method. The tissue distribution of chelerythrine and the effects on NQO1 following intragastric administration with $M$. cordata extracts in rats were examined.

Results: A total of twelve metabolites of chelerythrine were characterized by this approach in rat liver S9 and in vivo. The reduction of the iminium bond of chelerythrine and subsequent O-demethylation was the main metabolic pathway of chelerythrine in rat liver S9 while the reduction of the iminium bond of chelerythrine was the main metabolic pathway of chelerythrine in rats in vivo. After the rats were given intragastric administration, the low concentration residues of sanguinarine and chelerythrine in different rat tissues were found at $48 \mathrm{~h}$ after the last dose, suggesting that both compounds could be widely distributed in tissues. The results also indicated that $\mathrm{XO}$, NQO1, NQO2, and carbonyl reductase are involved in chelerythrine reduction. Macleaya cordata extracts treated female and male rats, respectively, showed different responses, inhibiting NQO1 activity in males, but inducing NQO1 activity in females. Chelerythrine had a weak impact on NQO1 activity, but sanguinarine inhibited NQO1 activity

Conclusion: Through studying the effects of cytosolic reductase inhibitors on chelerythrine reduction and the impact of chelerythrine and sanguinarine on the activity of NQO1 in vitro and in vivo, we clarified the potential drug interaction of Macleaya cordata extract in clinical application, so as to provide theoretical guidance for clinically safe medication. In addition, it provided a reference basis for the metabolic mechanism of chelerythrinein rats.

Keywords: Macleaya cordata, sanguinarine, chelerythrine, HPLC/QqTOF-MS, metabolites, reduction 


\section{INTRODUCTION}

Macleaya cordata (Willd.) R.Br. (Papaveraceae), a perennial plant, is listed as feed additive for animal production by the European Food Safety Authorityin 2004 (1). The powdered mixture of seeds, capsules, and leaves are the main components of the feed additive Sangrovit (2). The main active components of $M$. cordataare are Sanguinarine and chelerythrine (3). Quaternary benzo[c]phenanthrine alkaloids (QBAs) can improve the performance of an animal by eliminating the demand for antibiotics in the feed (3). Moreover, sanguiritrin in M. cordata is made up of QBAs in part containing sanguinarine and chelerythrine, which has been used as an antiplaque agent for mouthwash and toothpaste, and in veterinary preparation for the treatment of mastoiditis in cows. The efficacy and safety of sanguiritrinin oral care has been tested in many long-term and short-term clinical trials, e.g., using products presented by Paraskevas (4). Sanguiritrin was reportedly authorized by the Ministry of Health of the Union of Soviet Socialist Republics for industrial production and a wide range of medical uses for pharmaceutical formulations. In 1982, the pharmaceutical industry began to produce the drug (5). The extracts or compounds of $M$. cordata have significant pharmacological activities, but they are also toxic. Thus, the pharmacokinetic study of chelerythrine in animals is very important due to its biological effects and commercial use.

Previous pharmacokinetic studies have indicated that the bioavailability of chelerythrine was apparently low after oral administration. Kosina and their research group investigated the levels of chelerythrine in plasma, tissues and feces of pigs (6). The results showed that the chelerythrine was mostly excreted in feces and a small proportion of alkaloid was absorbed. Some in vitro metabolism studies also indicated that formation of the dihydrochelerythrine (DHCHE), which may be accompanied by special processes of O-demethylenation/O-demethylation, was the main mechanism behind the biotransformation of chelerythrine (7-9). Using the HPLC/QqTOF-MS method, Vacek et al. analyzed and then suggested the putative structures of 11 phase I and 5 phase II metabolites of chelerythrine using human hepatocytes (9). However, the in vivo metabolic profiles of chelerythrine have not yet been systematically elucidated. Detailed structural description of chelerythrine metabolites based on their product ions is rarely reported. Therefore, it is important to obtain more detailed descriptions of the metabolism of chelerythrine in vivo.

Chelerythrine and sanguinarine can be reabsorbed by QBAproducing plant cells and reduced to the less toxic dihydro derivativesm by sanguinarine reductase (10). Also, in animals and humans, the first step in the biotransformation of chelerythrine and sanguinarine appears to be transforming into their corresponding dihydro derivatives. Some studies have demonstrated that sanguinarine can be reduced to dihydrosanguinarine (DHSA) in the presence of enzyme cofactors NADH and NADPH $(11,12)$. In addition, our research team has demonstrated that in the liver cytosol, the reduction of the sanguinarine iminium bond occurs in two ways. One way is enzymatic reduction by possible carbonyl and/or quinone reductases in the hepatic cytosol, and the other is direct non-enzymatic reduction by $\mathrm{NAD}(\mathrm{P}) \mathrm{H}$ (13). We have also elucidated that the NQO1 was involved in the iminium bond reduction of sanguinarine, which in turn decreased cytotoxicity and sanguinarine-induced apoptosis (14). Numerous published studies have demonstrated that the main metabolic pathway of $\mathrm{SA}$ and $\mathrm{CHE}$ is reduction in the iminium bond, resulting in the formation of DHSA and $\operatorname{DHCHE}(7,15,16)$. Some studies have shown that the SA could be quickly metabolized into DHSA by iminium bond reduction which proceeds via two routes in the liver $(13,17)$. The NQO1 enzyme's involvement in the chelerythrine reduction, based on the similar structure of sanguinarine, requires further studies. As far as we know, there are no reports to evaluate the effects of chelerythrine and sanguinarine on NQO1.

Therefore, the first aim of this study was to investigate the metabolism of chelerythrine in vitro and in vivo. The second aim of the present study was to examine the metabolic enzymes that are involved in chelerythrine reduction using inhibition methods and effects on NQO1 activity in vitro. The third aim was to explore the tissue distribution residues in liver, heart, spleen, lung, and kidney, and the effects on NQO1 following intragastric administration with $M$. cordata extracts (containing $40 \%$ sanguinarine and $20 \%$ chelerythrine) for 3 weeks in rats.

\section{MATERIALS AND METHODS}

\section{Chemicals}

Chelerythrine (Content $\geq 95 \%$ ), sanguinarine (Content $\geq 95 \%$ ), and $M$. cordata extracts (containing 40\% sanguinarine, $20 \%$ chelerythrine and residual components include polysaccharides and amino acids) were obtained from Hunan Meikeda Co. (Changsha, China). Reduced metabolites DHCHE and DHSA were prepared using chelerythrine and sanguinarine reduction with $\mathrm{NaBH}_{4}$ in methanol, respectively. Deionized water was purified using a Milli-Q system (Bedford, MA, USA). NADPH and NADH were purchased from Roche Chemical Co. (Beijing, China). 7-Hydroxycoumarinand menadione were purchased from Sigma Chemical Co. (Content $>98 \%$, St. Louis, USA). Quercetin (Content $\geq 97 \%$ ) and dicoumarol (HPLC $\geq 95 \%$ ) were purchased from the National Institutes for Food and Drug Control (Beijing, China). HPLC-grade acetonitrile and formic acid were purchased from Merck (Darmstadt, Germany) and ROE (Newark, DE, USA), respectively. All other chemicals and reagents used were of the highest analytical grade.

\section{Metabolism of Chelerythrine in Rat Liver S9}

The rat liver S9 was prepared according to our previous metabolism study (18). To investigate the metabolites of chelerythrine in vitro, $2 \mathrm{mg} / \mathrm{mL}$ rat liver S9 protein, $5 \mathrm{mM} \mathrm{MgCl}_{2}$, and $2 \mathrm{mM}$ NADPH were mixed in a final volume of $200 \mu \mathrm{L}$ of $0.05 \mathrm{M}$ Tris- $\mathrm{HCl}$ buffer ( $\mathrm{pH}$ 7.4). Chelerythrine was dissolved in methanol (final amount in the reaction medium was $1 \%$ ). The reaction mixture was preincubated at $37^{\circ} \mathrm{C}$ for $5 \mathrm{~min}$, and then $20 \mu \mathrm{g} / \mathrm{mL}$ chelerythrine was added to initiate the reaction. The incubation mixtures without chelerythrine or NADPH were used as the blank control. $200 \mu \mathrm{L}$ ice-cold acetonitrile was added 
to stop the reaction after $1 \mathrm{~h}$. The mixture was vortexed and centrifuged at $12,000 \mathrm{~g}$ for $15 \mathrm{~min}$ at the end of the reaction. The clear supernatant was analyzed using HPLC/QqTOF-MS to identify metabolites.

\section{The Chelerythrine Iminium Bond Reduction by Rat Liver Cytosol}

The preparation of rat liver cytosol was isolated and incubated with chelerythrine according to our previous sanguinarine report (13). In brief, the incubation mixture consisted of $0.25 \mathrm{mg} / \mathrm{mL}$ cytosol protein, $5 \mathrm{mM} \mathrm{MgCl}_{2}, 100 \mu \mathrm{mol} / \mathrm{L}$ inhibitor, and $2 \mathrm{mM}$ $\mathrm{NADPH}$ in $0.05 \mathrm{M}$ Tris- $\mathrm{HCl}$ buffer ( $\mathrm{pH} 7.4$ ). The inhibitors were dicoumarol (quinone oxidoreductase 1), quercetin (quinone oxidoreductase 2, carbonyl reductase), menadione (aldehyde oxidase, carbonyl reductase), and 7-hydroxycoumarin (xanthine oxidase). The reaction was preincubated at $37^{\circ} \mathrm{C}$ for $5 \mathrm{~min}$. After the addition of $10 \mu \mathrm{g} / \mathrm{mL}$ chelerythrine, the reaction was started. The incubation mixtures without the inhibitor or cytosol protein acted as the blank control. The reaction was stopped by adding $200 \mu \mathrm{L}$ ice-cold acetonitrile after $15 \mathrm{~min}$, and the mixture was vortexed and centrifuged at $12,000 \mathrm{~g}$ for $15 \mathrm{~min}$. The clear supernatant was analyzed by HPLC for the quantitative results of DHCHE.

\section{Animals, Drug Administration, and Sample Collection}

Sprague-Dawley (SD) rats were purchased from Hunan SLRC Laboratory Animal Center (Changsha, China). The rats were acclimatized for 5 days under a standardized light $(12 \mathrm{~h}$ light $/ 12 \mathrm{~h}$ dark) and temperature $\left(26^{\circ} \mathrm{C}\right)$ environment in Hunan Research Center of Laboratory Animals (Changsha, China), and ate standard feed freely. All animal care and experimental protocols were conducted in accordance with the Guide for the Care and Use of Hunan Provincial Laboratory Animal Public Service Center and approved by the Institutional animal care and use committee of Hunan Research Center for drug safety evaluation, Changsha, China (permit number SYXK 2010-0005).

\section{In vivo Metabolism}

Ten SD rats (160-180g, five males and five females) were individually placed in stainless steel metabolic cages. All rats were fasted for $12 \mathrm{~h}$ and had free access to water before drug administration. Chelerythrine in water with the dissolving aid of Tween-80 was intragastrically administered to rats at a dose of $10 \mathrm{mg} / \mathrm{kg}$. One milliliter whole blood samples were collected from retro orbital sinus with a heparinized blood collection tube at $3 \mathrm{~h}$ following drug dosing. Each collected blood sample was centrifuged at $3,000 \mathrm{rpm}$ at $4^{\circ} \mathrm{C}$ for $10 \mathrm{~min}$ to obtain plasma samples. Urine and feces of rats were collected during 0-12 and $12-24 \mathrm{~h}$ after administration, respectively. All samples were collected from female and male rats and stored at $-70^{\circ} \mathrm{C}$.

\section{Tissue Distribution}

Tissue distribution was carried out in eighteen SD rats (160$180 \mathrm{~g}$, nine males and nine females). Twelve rats (six male and six female) were intragastrically administered with $M$. cordata extracts at a single dosage of $5 \mathrm{mg} / \mathrm{kg}$ (containing about $2 \mathrm{mg} / \mathrm{kg}$ dose of sanguinarine and $1 \mathrm{mg} / \mathrm{kg}$ dose of chelerythrine) in water with the dissolving aid of Tween- 80 for 3 weeks. Three male and three female rats were given the same amount of water as the blank control group by intragastric administration. Six rats (three male and three female) in the control group and six rats (three male and three female) in the drug group were sacrificed at $24 \mathrm{~h}$ after last dosing, and the rest of the rats were sacrificed by cervical dislocation at $48 \mathrm{~h}$ after the administration. Tissue samples including cecal contents, lung, heart, liver, kidney, and spleen were collected at 24 and $48 \mathrm{~h}$ after the last administration and stored at $-70^{\circ} \mathrm{C}$.

\section{Sample Pretreatment}

The preparations of plasma, urine, feces, and tissues were pretreatments according to our current study (19).

\section{Instruments and Analytical Conditions HPLC/QqTOF-MS}

The chromatographic separation was conducted using an Agilent 1290 HPLC system with a Hypersil GOLD column $(150 \times$ $2.1 \mathrm{~mm}$ I.D.; particle size $5 \mu \mathrm{m}$ ). The mobile phase was composed of $0.1 \%$ formic acid water (mobile phase A) and acetonitrile (mobile phase $\mathrm{B}$ ), and the gradient elution procedure was as follows: $10 \% \mathrm{~B}$ (0-5 min), 10-90\% B (5-20 min), 90\% B (20$25 \mathrm{~min}), 10 \% \mathrm{~B}(25-30 \mathrm{~min})$, and the flow rate of $0.3 \mathrm{~mL} / \mathrm{min}$. The injection volume was $5 \mu \mathrm{L}$.

The Agilent 6530 Q-TOF-MS mass spectrometer equipped with electro-spray ionization (ESI) source operated in positive ionization mode. Nitrogen was used as atomization gas, and the flow rate was $9 \mathrm{~L} / \mathrm{min}$. The parameters of the mass spectrometer were as follows: nozzle voltage $1 \mathrm{kv}$, capillary voltage $4.0 \mathrm{kv}$, sheath gas temperature $350^{\circ} \mathrm{C}$, sheath gas flow rate $11 \mathrm{~L} / \mathrm{min}$, nebulizer voltage $35 \mathrm{psig}$. The quarantine window was set at $1 \mathrm{amu}$. The instrument automatically performed the internal mass calibration though the automated calibrate transfer system. In positive ion mode, the calibrating solution contained the internal reference masses at $\mathrm{m} / \mathrm{z} 121.0508$ and 922.0098. All the data acquisition was controlled by Agilent Mass Hunter software (version B.01.03 Build 1.3.157.0 2), and the Agilent Mass Hunter software (Qualitative Analysis B.04.0) was used to accurately take mass measurements of each peak from the total ion chromatograms. Then, these metabolites were subjected to accurate EIC, and the acceptance or rejection was decided according to the peak appearing in the EIC. Structural elucidations of chelerythrine metabolites were carried out on the basis of the mass change from the metabolite or parent drug, the predicted elemental compositions, and the interpretation of accurate MS/MS spectra.

\section{HPLC-MS/MS}

The HPLC-MSMS method was established for the determination of sanguinarine and chelerythrine in tissues using the Agilent series 1290 Infinity HPLC system with a $1.8 \mu \mathrm{m}$ Agilent Zorbax $\mathrm{SB}_{-} \mathrm{C}_{18}(2.1 \times 50 \mathrm{~mm})$ column. The mobile phase consisted of $0.1 \%$ formic acid water (mobile phase A) and acetonitrile (mobile phase $\mathrm{B}$ ), and the linear gradient at the flow rate of 
$0.3 \mathrm{~mL} / \mathrm{min}$ was as follows: $0-4 \mathrm{~min}, 15-17 \% \mathrm{~B} ; 4-6 \mathrm{~min}, 17-$ $35 \% \mathrm{~B} ; 6-8 \mathrm{~min}, 35 \% \mathrm{~B}$. The injection volume was $2 \mu \mathrm{L}$. An Agilent 6460 QQQ mass spectrometer equipped with ESI was operated in positive mode with multiple reactions monitoring mode. The controls of the operating parameters were as follows: capillary voltage, 3,500 V; EM voltage, $200 \mathrm{~V}$; dry gas $\left(\mathrm{N}_{2}\right)$ flow rate, $12 \mathrm{~L} / \mathrm{min}$; ion source temperature, $350^{\circ} \mathrm{C}$; nebulizer, 25 psi. The quantitative transitions, collision energy (CE) and conevoltage for sanguinarine were $332.1>274.0,34 \mathrm{eV}$ and $141 \mathrm{~V}$, respectively. The quantitative transitions, $\mathrm{CE}$ and cone-voltage for ALL were, $348.1>332.0,30 \mathrm{eV}$ and $146 \mathrm{~V}$, respectively.

Using optimal conditions, the retention times of sanguinarine and chelerythrine were 5.9 and $6.5 \mathrm{~min}$, respectively. The proposed method was validated by evaluation of specificity, accuracy, precision, LOD, and LOQ. Using this method, the limit of quantification of sanguinarine and chelerythrine in tissues was estimated to be $0.5 \mathrm{ng} / \mathrm{g}$. The average accuracies of intraand inter-day assay fell within $90.7-105.0 \%$ and $101.6-114.0 \%$, respectively. The mean intra- and inter-day precisions were 14.6 and $9.3 \%$ (RSD $<15 \%$ ), respectively. This method was suitable for accurately quantitatively determining the tissue distribution of sanguinarine and chelerythrine.

\section{HPLC Method}

DHCHE was quantified using a Shimadzu LC- 2010AHT system (Shimadzu Co., Kyoto, Japan), which was equipped with a LC-10ADvp pump, a SIL-10ADvp autosampler, and a SOD$10 \mathrm{ADvp}$ detector. Chelerythrine and $\mathrm{DHCHE}$ were separated on a Phenomenex Luna 5u C18(2) 100 A (4.6 × 250 mm I.D.; particle $5 \mu \mathrm{m}$; Phenomenex Co. USA). The mobile phase consisted of a $30 / 70(\mathrm{v} / \mathrm{v})$ mixture of solvent $\mathrm{A}(0.2 \%$ aqueous acetic acid solution) and solvent B (acetonitrile). The injection dose was 10 $\mu \mathrm{l}$ and the flow rate was $1 \mathrm{~mL} / \mathrm{min}$. The column temperature was set to $35^{\circ} \mathrm{C}$ and the detection wavelength was set to $285 \mathrm{~nm}$. The DHCHE standard curve varied linearly in the concentration range from 0.050 to $10 \mu \mathrm{g} / \mathrm{mL}$. The recovery, inter- and intraassay coefficients of variation of DHCHE was $96.8 \pm 5.2,7.4$ and $3.9 \%$ at $0.1 \mu \mathrm{g} / \mathrm{mL}$, respectively. The lower limit of quantification was $0.050 \mu \mathrm{g} / \mathrm{mL}$.

\section{Assay for NAD(P)H Quinone Oxidoreductase (NQO1) Activity}

The reaction mixture contained $50 \mu \mathrm{g} / \mathrm{mL}$ rat liver cytosol, $0.2 \mathrm{mM} \mathrm{NADH}, 50 \mathrm{mM}$ Tris- $\mathrm{HCl}(\mathrm{pH} 7.4)$ and $40 \mu \mathrm{M} 2,6-$ dichloro- phenolindophenol (DCPIP) in a final volume of 210 $\mu \mathrm{L}$. The sample was transferred into the wells of the microplate with a pipette, and was measured with or without dicoumarol. Any change in absorbance was monitored at $620 \mathrm{~nm}$, and NQO1 activity was calculated by using the extinction coefficient for DCPIP $\left(\varepsilon=21 \mathrm{mM}^{-1} \mathrm{~cm}^{-1}\right)$ and expressed as nanomles of DCPIP reduced per minute per milligram of protein.

\section{In vitro Inhibition Experiments}

The inhibitory effects of sanguinarine and chelerythrine were determined by the incubation of the reaction mixture with or without substrate. The incubation mixtures for inhibition studies contained $40 \mu \mathrm{M}$ DCPIP, $50 \mu \mathrm{g} / \mathrm{mL}$ rat liver cytosol and
$0.2 \mathrm{mM} \mathrm{NADH}$ and different concentrations of sanguinarine or chelerythrine $(0-40 \mu \mathrm{M})$ to determine the $\mathrm{IC}_{50}$ values. The $\mathrm{K}_{\mathrm{i}}$ values (inhibition constant) were different concentrations of DCPIP (5-40 $\mu \mathrm{M})$ with sanguinarine. All of the incubations and sample preparations were carried out as described for the NQO1 assay above.

\section{Statistical Analysis}

All results were tested by one-way analysis of variance and Dunnett's multiple comparison tests with Graphpad Prism6.0. Differences between means were determined at the $p<0.05$ or $p<0.01$ levels for all analyses and indicated with * and **, respectively. Data were represented as mean \pm S.D. of at least three replicate experiments.

\section{RESULTS}

\section{Structure Elucidation of Chelerythrine Metabolites in Rat Liver S9}

The accurate extracted ion chromatograms (EICs) of the chelerythrine metabolites in rat liver S9 are shown in Figures 1A-G. Eight chelerythrine metabolites (Ch1-Ch8) were detected in rat liver $\mathrm{S} 9$.

Understanding the fragmentation pattern of the drug substance is the first step in elucidating structures of chelerythrine metabolites. The fragmentation pattern of chelerythrine was analyzed by mass spectrometry, which provided a reference for structural identification of metabolites (shown in Table 1). It is easy to propose its product ion structures based on the structure of the parent drug and the predicated elemental compositions. As seen in Figure 2, the $\mathrm{MS}^{2}$ spectra of chelerythrine produces product ions at $\mathrm{m} / z 333$ and 332, which were formed through the loss of $\mathrm{CH}_{3}$ and $\mathrm{CH}_{4}$ from the quaternary ammonium ion $\mathrm{M}^{+}$, respectively. The ion at $\mathrm{m} / z 304$ was formed due to the loss of CO from $\mathrm{m} / z$ 332. The ion at $\mathrm{m} / z$ 318 lost $\mathrm{CH}_{3}$ from the $m / z$ 333. With the further loss of $\mathrm{CO}$, the ion formed $m / z 290$.

The retention time of metabolite Ch1 was $18.4 \mathrm{~min}$, and it showed the $[\mathrm{M}+\mathrm{H}]^{+}$ion at $m / z 350$, which was $2 \mathrm{Da}$ higher than chelerythrine. The $\mathrm{MS}^{2}$ spectrum of Ch1 (see Table 1) produced ions at $m / z 335$ and 334, which were formed due to the loss of $\mathrm{CH}_{3}$ and $\mathrm{CH}_{4}$ from $m / z 350$, respectively. The ion at $m / z 318$ was produced by the loss of $\mathrm{CH}_{3} \mathrm{OH}$ from $\mathrm{m} / z$ 350. The ion at $\mathrm{m} / z 304$ was formed through the loss of $\mathrm{CH}_{2} \mathrm{O}$ from $\mathrm{m} / z 334$. The retention time of Ch1 was the same, $[\mathrm{M}+\mathrm{H}]^{+}$ion and $\mathrm{MS}^{2}$ spectrum as authentic DHCHE. As a result, Ch1 was identified as DHCHE.

The retention time of metabolite $\mathrm{Ch} 2$ was $16.0 \mathrm{~min}$, and it showed the $[\mathrm{M}+\mathrm{H}]^{+}$ion at $\mathrm{m} / z$ 336, which was $12 \mathrm{Da}$ lower than chelerythrine, thereby indicating that it could be chelerythrine demethylenation metabolite or DHCHE O-demethylation metabolite. The $\mathrm{MS}^{2}$ spectrum of Ch2 (see Table 1) produced ions at $m / z 321$ and 320, which were formed through the loss of $\mathrm{CH}_{3}$ and $\mathrm{CH}_{4}$ from $\mathrm{m} / z$ 336, respectively. The ion at $m / z 305$ may be formed due to the loss of $\mathrm{CH}_{3}$ from $\mathrm{m} / z$ 320. The ion at $m / z 304$ was produced by the loss of $\mathrm{CH}_{3} \mathrm{OH}$ from $\mathrm{m} / z$ 336. The ion at $\mathrm{m} / z 304$ saw further loss of CO, forming 

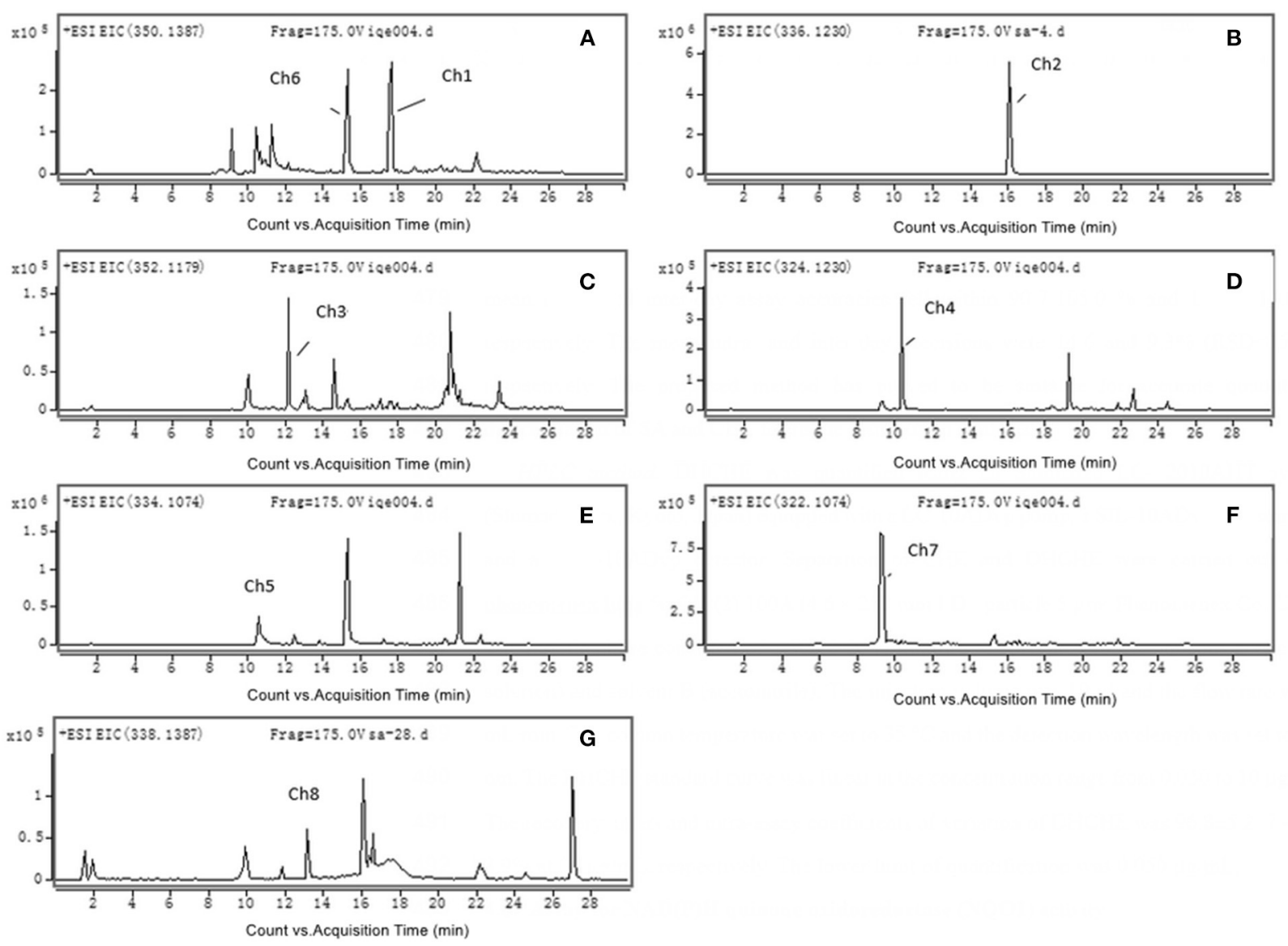

FIGURE 1 | Accurate MS mass spectra chelerythrine metabolites in rat liver S9: (A) Ch1 (m/z 350); (B) Ch2 (m/z 336) and Ch6 (m/z 350); (C) Ch3 (m/z 352); (D) Ch4 (m/z 324); (E) Ch5 (m/z 334); (F) Ch7 (m/z 322); (G) Ch8 ( $\mathrm{m} / \mathrm{z} 338)$.

$m / z$ 276. Moreover, the $\mathrm{MS}^{2}$ spectrum of Ch2 showed product ions at $\mathrm{m} / z$ 321, 320, 304 (see Table 1), which were 14 Da lower than the product ions at $m / z 335,334,318$ of DHCHE. Therefore, metabolite $\mathrm{Ch} 2$ could be DHCHE O-demethylation metabolite located at the positions on the $\mathrm{C} 7$ or $\mathrm{C} 8$ bond.

The retention time of metabolite Ch3 was $12.2 \mathrm{~min}$, and it showed the $[\mathrm{M}+\mathrm{H}]^{+}$ion at $m / z 352$, which was $16 \mathrm{Da}$ higher than Ch2. The $\mathrm{MS}^{2}$ spectrum of Ch3 (see Table 1) produced ions at $m / z 337,336,321,320,292$, which were $16 \mathrm{Da}$ higher than the product ions at $m / z 321,320,305,304,276$ of Ch2. The $\mathrm{MS}^{2}$ spectrum of Ch3 produced ions at $\mathrm{m} / z 337$ and 336, which were formed due to the loss of $\mathrm{CH}_{3}$ and $\mathrm{CH}_{4}$ from $\mathrm{m} / z$ 352, respectively. The ion at $\mathrm{m} / z 321$ was formed through the loss of $\mathrm{CH}_{3}$ from $m / z 336$. The ion at $m / z 320$ was produced by the loss of $\mathrm{CH}_{3} \mathrm{OH}$ from $m / z 352$. The ion at $\mathrm{m} / z 320$ saw a further loss of CO, forming $m / z 292$. Based on these results, we preliminarily identified that $\mathrm{Ch} 3$ was a hydroxylation metabolite of Ch2 located at the positions on the phenyl ring.

The retention time of metabolite Ch4 was $10.4 \mathrm{~min}$, and it showed the $[\mathrm{M}+\mathrm{H}]^{+}$ion at $m / z 324$, which was $12 \mathrm{Da}$ lower than Ch2, thus suggesting that it may be Ch2 demethylenation metabolite. The $\mathrm{MS}^{2}$ spectrum of Ch4 (see Table 1) produced ions at $m / z 309$ and 308, which were formed due to loss of $\mathrm{CH}_{3}$ and $\mathrm{CH}_{4}$ from $m / z$ 324, respectively. The ion at $m / z$ 293 may be formed through the loss of $\mathrm{CH}_{3}$ from $m / z 308$. The ion at $m / z 264$ was produced by the loss of $\mathrm{CHO}$ from $\mathrm{m} / z$ 308. Moreover, the $\mathrm{MS}^{2}$ spectrum of Ch4 showed product ions at $m / z 309,308,293$, which were $12 \mathrm{Da}$ lower than the product ions at $m / z 321,320,305$ of Ch2. Therefore, metabolite Ch4 could be Ch2 O-demethylenation metabolite at the methylenedioxy group.

The retention time of metabolite Ch5 was $11.1 \mathrm{~min}$, and it showed the $[\mathrm{M}]^{+}$ion at $m / z 334$, which was $14 \mathrm{Da}$ lower than chelerythrine. We did not detect the $[\mathrm{M}-16]^{+}$ion, so the product ions could not be $\mathrm{N}$-demethylenatedchelerythrine metabolite, but were probably $\mathrm{O}$-demethylenatedchelerythrine metabolite. The MS ${ }^{2}$ spectrum of Ch5 (see Table 1) produced ions at $\mathrm{m} / \mathrm{z}$ 319 , which were formed due to the loss of $\mathrm{CH}_{3}$ from $\mathrm{m} / z 334$. The ion at $m / z 304$ was formed through the loss of $\mathrm{CH}_{3}$ from $\mathrm{m} / z$ 319. The ion at $\mathrm{m} / z 319$ saw further loss of CO, forming $\mathrm{m} / z$ 291. The ion at $\mathrm{m} / z 276$ was produced by the loss of $\mathrm{CH}_{3}$ from $\mathrm{m} / z$ 304. Consequently, metabolite Ch5 was identified as $\mathrm{O}$-demethylated chelerythrine metabolite located at the positions on the $\mathrm{C} 7$ or $\mathrm{C} 8$ bond. 


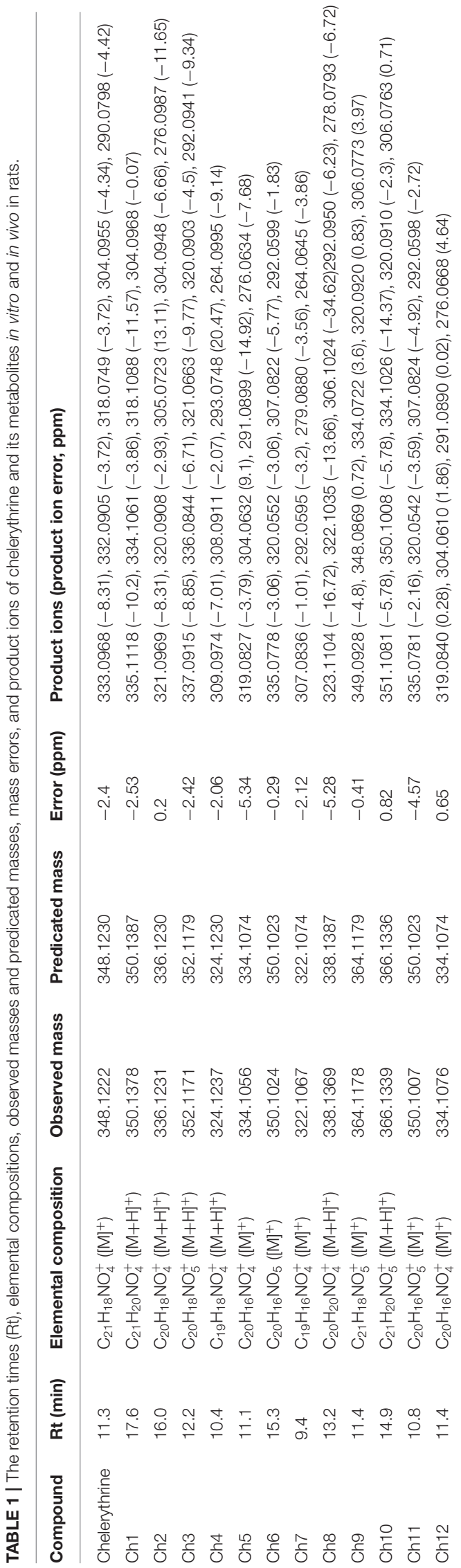

The retention time of the metabolite Ch6 was $15.3 \mathrm{~min}$, and it showed the $[\mathrm{M}]^{+}$ion at $m / z 350$, which was $16 \mathrm{Da}$ higher than Ch5. Ch6 might be a hydroxylated derivative of Ch5. The $\mathrm{MS}^{2}$ spectrum of Ch6 (see Table 1) produced ions at $\mathrm{m} / z$ 335, which were formed due to the loss of $\mathrm{CH}_{3}$ from $m / z$ 350. The ion at $\mathrm{m} / z 335$ saw further loss of CO, forming $\mathrm{m} / \mathrm{z} 307$. The ion at $m / z 320$ was formed though the loss of $\mathrm{CH}_{3}$ from $m / z 335$. The ion at $m / z 320$ saw further loss of CO, forming $m / z 292$. Moreover, the ions of Ch6 showed a shift of $+16 \mathrm{Da}$ from those of Ch5. As a result, the possible hydroxyl could be located on a phenyl ring. Based on these results, the structure of Ch6 was tentatively identified a hydroxylation metabolite of Ch5 located at the positions on the phenyl ring.

The retention time of metabolite $\mathrm{Ch} 7$ was $9.4 \mathrm{~min}$, and it showed the $[\mathrm{M}]^{+}$ion at $m / z 322$, which was 12 Da lower than those from Ch5, corresponding to possible O-demethylenated Ch5 metabolite. The $\mathrm{MS}^{2}$ spectrum of $\mathrm{Ch} 7$ produced ion at $\mathrm{m} / z$ 307 , which were formed due to the loss of $\mathrm{CH}_{3}$ from $\mathrm{m} / z 322$. The ion at $m / z 307$ saw further loss of $\mathrm{CH}_{3}$, forming $\mathrm{m} / z 292$. The ion at $m / z 279$ was formed though the loss of COfrom $\mathrm{m} / z$ 307. The ion at $m / z 264$ was produced by the loss of CO from $\mathrm{m} / z$ 292. Therefore, we preliminarily identified that metabolites Ch7 was the ring-cleavage of $\mathrm{Ch} 5$, and then $\mathrm{O}$-demethylenation at the methylenedioxy group.

The retention time of metabolite Ch8 was $13.2 \mathrm{~min}$, and it showed the $[\mathrm{M}+\mathrm{H}]^{+}$ion at $m / z$ 338, which was $12 \mathrm{Da}$ lower than DHCHE, thus suggesting that it may be $\mathrm{DHCHE}$ demethylenation metabolite. The $\mathrm{MS}^{2}$ spectrum of Ch8 (see Table 1) produced ions at $m / z 323$ and 322, which were formed due to loss of $\mathrm{CH}_{3}$ and $\mathrm{CH}_{4}$ from $\mathrm{m} / z$ 338, respectively. The ion at $m / z 306$ was formed though the loss of $\mathrm{CH}_{3} \mathrm{OH}$ from $m / z 338$. The ion at $m / z 306$ saw further loss of CO, forming $m / z 278$. The ion at $\mathrm{m} / z 292$ was produced by the loss of $\mathrm{CH}_{2} \mathrm{O}$ from $\mathrm{m} / z 322$. Therefore, metabolite Ch8 could be DHCHE O-demethylenation metabolite at the methylenedioxy group.

\section{Metabolite Profiles of Chelerythrine in Plasma, Feces, and Urine in Rats After Intragastric Administration of Chelerythrine}

The chelerythrine metabolites detected in plasma, feces, and urine of rats are shown in Table 2. Three hours after intragastric administration of chelerythrine, no parent drug and metabolites were detected in the plasma of the male and female rats. Only the metabolites $\mathrm{Ch} 2$ and $\mathrm{Ch} 5$ were found in the urine of $0-$ $12 \mathrm{~h}$ male rats. Eight and seven metabolites were observed in the feces of female and male rats during $0-12 \mathrm{~h}$ after intragastric administration of chelerythrine, respectively. They were Ch1, Ch2, Ch5, Ch8, Ch9, Ch10, Ch11, and Ch12, and seven of these metabolites were found in male rat feces of $0-12 \mathrm{~h}$ except for Ch10. Supplementary Figure 1 shows the accurate EICs of female rat feces after a single dose oforal administration of chelerythrine for 0-12 h (See Supplemental Material). Except for chelerythrine, only Ch1 was observed in the feces of female rats from 12 to $24 \mathrm{~h}$ after intragastric administration of chelerythrine. 

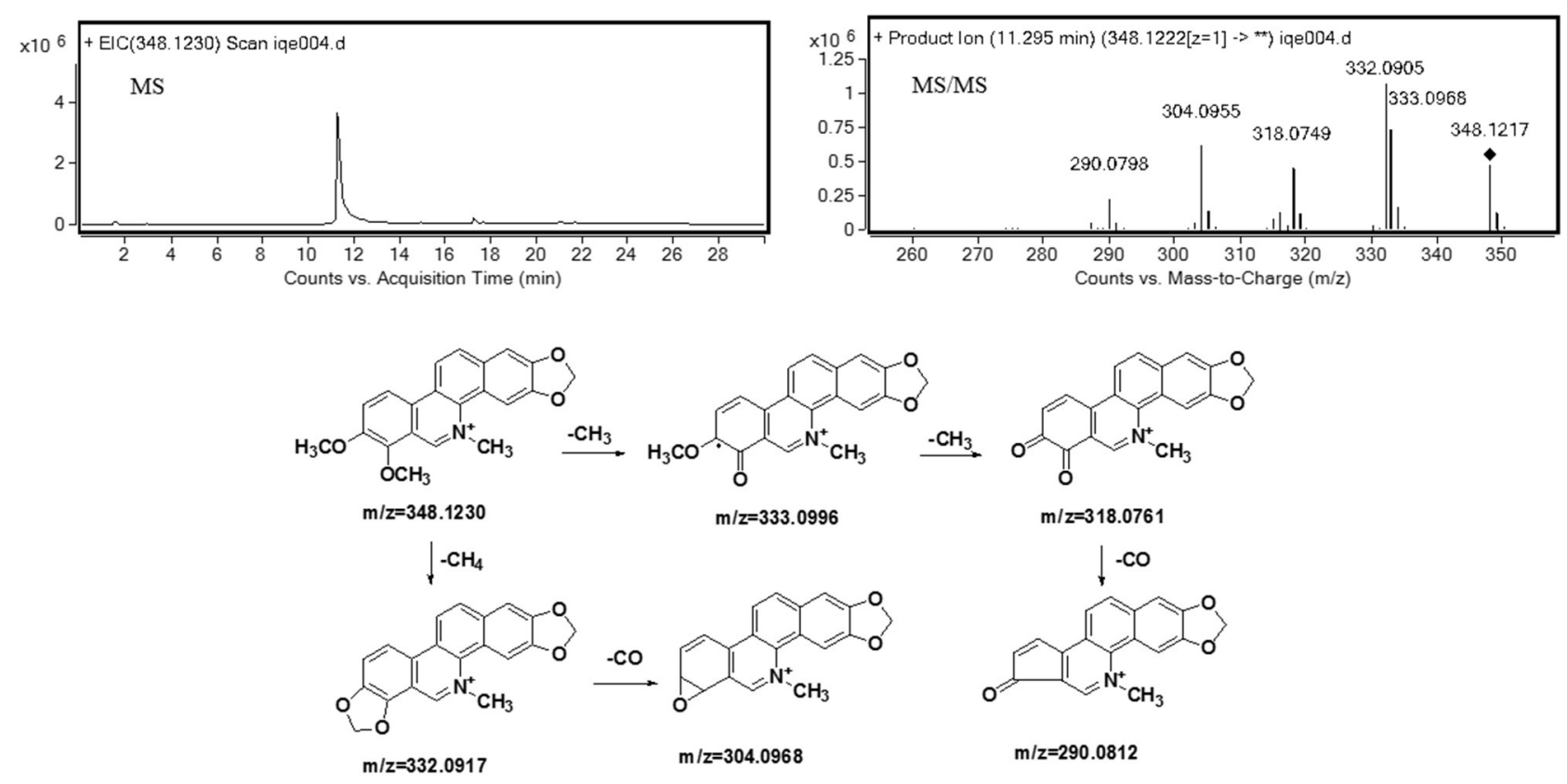

FIGURE 2 | Accurate MS, MS² spectra, and proposed fragmentation pathways of chelerythrine.

\section{Structure Elucidation of Chelerythrine Metabolites in Rat in vivo}

Except for four metabolites (Ch1, Ch2, Ch5, and Ch8) observed in rat liver S9, four metabolites (Ch9-Ch12) were also found in vivo. The retention time of Metabolite Ch9 was $11.4 \mathrm{~min}$, and it showed the $[\mathrm{M}]^{+}$ion at $m / z 364$, which was $16 \mathrm{Da}$ higher than chelerythrine. Ch9 might be a hydroxylated derivative of chelerythrine. The $\mathrm{MS}^{2}$ spectra of Ch9 (see Table 1) produced ions at $m / z 349$ and 348, which were formed due to the loss of $\mathrm{CH}_{3}$ and $\mathrm{CH}_{4}$ from $m / z 364$, respectively. The ion at $\mathrm{m} / z 320$ was formed though the loss of CO from $\mathrm{m} / z$ 348. The ion at $\mathrm{m} / z$ 334 lost $\mathrm{CH}_{3}$ from the $m / z$ 349. With the further the loss of CO, the ion formed $\mathrm{m} / \mathrm{z}$ 306. Therefore, metabolite Ch9 could be a hydroxylation metabolite of chelerythrine located at the positions on the phenyl ring.

The retention time of metabolite Ch10 was $14.9 \mathrm{~min}$, and it showed the $[\mathrm{M}+\mathrm{H}]^{+}$ion at $m / z 366$, which was $16 \mathrm{Da}$ higher than DHCHE. Ch10 might be a hydroxylated metabolite of DHCHE. The MS ${ }^{2}$ spectra of Ch10 (see Table 1) produced ions at $m / z 351$ and 350, which were formed due to the loss of $\mathrm{CH}_{3}$ and $\mathrm{CH}_{4}$ from $m / z$ 366, respectively. The ion at $m / z 334$ was formed though the loss of $\mathrm{CH}_{3} \mathrm{OH}$ from $\mathrm{m} / z$ 366. With the further the loss of CO, the ion formed $\mathrm{m} / z$ 306. The ion at $\mathrm{m} / \mathrm{z}$ 320 was produced by the loss of $\mathrm{CH}_{2} \mathrm{O}$ from $\mathrm{m} / z$ 350. Therefore, metabolite Ch10 could be a hydroxylation metabolite of DHCHE located at the positions on the phenyl ring.

The retention time of metabolite Ch11 was $10.8 \mathrm{~min}$, and it showed the $[\mathrm{M}]^{+}$ion at $m / z 350$, which was also 16 Da higher than Ch5. Ch11 might be a hydroxylated derivative of Ch5. Ch11 and Ch6 had the same $\mathrm{MS}^{2}$ spectrum and $[\mathrm{M}]^{+}$ion. As a result, Ch11 was preliminarily identified as an isomer of Ch6. The retention time of metabolite Ch12 was $11.4 \mathrm{~min}$, and it showed the $[\mathrm{M}]^{+}$ion at $m / z 334$, and Ch12 and Ch5 had the same MS ${ }^{2}$ spectrum and $[\mathrm{M}]^{+}$ion. Consequently, Ch12 was preliminarily identified as an isomer of Ch5.

\section{Metabolism and Tissue Distribution of Sanguinarine and Chelerythrine After Intragastric Administration of M. cordata Extracts}

As shown in Table 2, no metabolites of sanguinarine and chelerythrine were found in 24 and $48 \mathrm{~h}$ rat tissues after 3 weeks of intragastric administration of $M$. cordata extracts (containing $40 \%$ sanguinarine and $20 \%$ chelerythrine). The metabolite profiles of sanguinarine in plasma, urine, and feces in rats were examined because the $M$. cordata extracts contained sanguinarine. No parent drug or metabolites were observed in rat plasma at $3 \mathrm{~h}$ and urine of $0-24 \mathrm{~h}$ after intragastric administration of $M$. cordata extracts. In addition to the parent drug, two metabolites were observed in the feces of both male and female rats during 0-24 h (See Supplementary Figure 2).

As seen in Table 3, the retention time of sanguinarine was $11.0 \mathrm{~min}$, and it showed the $[\mathrm{M}]^{+}$ion at $\mathrm{m} / z$ 332. The ions at $\mathrm{m} / z 317$ and $\mathrm{m} / z 304$ were formed due to the loss of $\mathrm{CH}_{3}$ and $\mathrm{CO}$ from $m / z 332$, respectively. The ion at $m / z 304$ further lost $\mathrm{CH}_{2} \mathrm{O}$, forming $m / z 274$. And the ion at $m / z 246$ lost CO from the ion at $m / z 274$.

The retention time of Metabolite S1 was $18.0 \mathrm{~min}$, and it showed the $[\mathrm{M}+\mathrm{H}]^{+}$ion at $m / z 334$ (see Table 3), which was $2 \mathrm{Da}$ higher than sanguinarine. The ions at $\mathrm{m} / z 319$ and $m / z$ 318 were formed due to loss of $\mathrm{CH}_{3}$ and $\mathrm{CH}_{4}$ from $\mathrm{m} / z$ 334, 
TABLE 2 | Summary of chelerythrine metabolites detected in the plasma, urine, feces, and tissues of rats.

\begin{tabular}{|c|c|c|c|c|c|c|c|c|c|c|c|c|c|c|c|c|c|c|c|c|}
\hline \multirow[t]{3}{*}{ Compound } & \multicolumn{5}{|c|}{ Female } & \multicolumn{5}{|c|}{ Male } & \multirow{2}{*}{\multicolumn{2}{|c|}{ Kidney }} & \multirow[b]{3}{*}{$24 \mathrm{~h}$} & \multirow[b]{3}{*}{$48 \mathrm{~h}$} & \multirow[b]{3}{*}{$24 \mathrm{~h}$} & \multirow[b]{3}{*}{$48 \mathrm{~h}$} & \multirow[b]{3}{*}{$24 \mathrm{~h}$} & \multirow[b]{3}{*}{$48 \mathrm{~h}$} & \multirow[b]{3}{*}{$24 \mathrm{~h}$} & \multirow[b]{3}{*}{$48 \mathrm{~h}$} \\
\hline & Plasma & Urine & Feces & Plasma & Urine & Feces & Heart & Liver & Spleen & Lung & & & & & & & & & & \\
\hline & $3 \mathrm{~h}$ & $0-12 \mathrm{~h}$ & $12-24 \mathrm{~h}$ & $0-12 \mathrm{~h}$ & $12-24 \mathrm{~h}$ & $3 \mathrm{~h}$ & $0-12 \mathrm{~h}$ & $12-24 \mathrm{~h}$ & $0-12 \mathrm{~h}$ & $12-24 \mathrm{~h}$ & $24 \mathrm{~h}$ & $48 \mathrm{~h}$ & & & & & & & & \\
\hline Chelerythrine & ND & ND & ND & $\sqrt{ }$ & $\sqrt{ }$ & ND & ND & ND & $\sqrt{ }$ & $\sqrt{ }$ & ND & ND & ND & ND & ND & ND & ND & ND & ND & ND \\
\hline DHCHE & ND & ND & ND & $\sqrt{ }$ & $\sqrt{ }$ & ND & ND & ND & $\sqrt{ }$ & ND & ND & ND & ND & ND & ND & ND & ND & ND & ND & ND \\
\hline Ch2 & ND & ND & ND & $\sqrt{ }$ & ND & ND & $\sqrt{ }$ & ND & $\sqrt{ }$ & ND & ND & ND & ND & ND & ND & ND & ND & ND & ND & ND \\
\hline Ch3 & ND & ND & ND & ND & ND & ND & ND & ND & ND & ND & ND & ND & ND & ND & ND & ND & ND & ND & ND & ND \\
\hline Ch4 & ND & ND & ND & ND & ND & ND & ND & ND & ND & ND & ND & ND & ND & ND & ND & ND & ND & ND & ND & ND \\
\hline Ch5 & ND & ND & ND & $\sqrt{ }$ & ND & ND & $\sqrt{ }$ & ND & $\sqrt{ }$ & ND & ND & ND & ND & ND & ND & $N D$ & ND & ND & ND & ND \\
\hline Ch6 & ND & ND & ND & ND & ND & ND & ND & ND & ND & ND & ND & ND & ND & ND & ND & ND & ND & ND & ND & ND \\
\hline Ch7 & ND & ND & ND & ND & ND & ND & ND & ND & ND & ND & ND & ND & ND & ND & ND & ND & ND & ND & ND & ND \\
\hline Ch8 & ND & ND & ND & $\sqrt{ }$ & ND & ND & ND & ND & $\sqrt{ }$ & ND & ND & ND & ND & ND & ND & ND & ND & ND & ND & ND \\
\hline Ch9 & ND & ND & ND & $\sqrt{ }$ & ND & ND & ND & ND & $\sqrt{ }$ & ND & ND & ND & ND & ND & ND & ND & ND & ND & ND & ND \\
\hline Ch10 & ND & ND & ND & $\sqrt{ }$ & ND & ND & ND & ND & ND & ND & ND & ND & ND & ND & ND & ND & ND & ND & ND & ND \\
\hline Ch11 & ND & ND & ND & $\sqrt{ }$ & ND & ND & ND & ND & $\sqrt{ }$ & ND & ND & ND & ND & ND & ND & ND & ND & ND & ND & ND \\
\hline Ch12 & ND & ND & ND & $\sqrt{ }$ & ND & ND & ND & ND & $\sqrt{ }$ & ND & ND & ND & ND & ND & ND & ND & ND & ND & ND & ND \\
\hline
\end{tabular}

Ch followed by number, metabolite; $\sqrt{ }$, detected; ND, not detected.

TABLE 3 | The retention times (Rt), elemental compositions, observed masses and predicated masses, mass errors, and product ions of sanguinarine and its metabolites in vivo in rats.

\begin{tabular}{lllllll}
\hline Compound & Rt (min) & Elemental composition & Observed mass & Predicated mass & Error (ppm) & Product ions (product ion error, ppm) \\
\hline Sanguinarine & 11.0 & $\mathrm{C}_{20} \mathrm{H}_{14} \mathrm{NO}_{4}^{+}\left([\mathrm{M}]^{+}\right)$ & 332.0911 & 332.0917 & -1.91 & $317.0672(-3.34), 304.0955(-4.34), 274.0853(-3.48), 246.0903(-4.23)$ \\
S1 & 18.0 & $\mathrm{C}_{20} \mathrm{H}_{16} \mathrm{NO}_{4}^{+}\left([\mathrm{M}+\mathrm{H}]^{+}\right)$ & 334.1074 & 334.1074 & -0.05 & $319.0817(-6.95), 318.0755(-1.84), 304.0944(-7.98), 276.1012(-2.56)$ \\
S2 & 15.3 & $\mathrm{C}_{20} \mathrm{H}_{14} \mathrm{NO}_{5}^{+}\left([\mathrm{M}]^{+}\right)$ & 348.0866 & 348.0866 & -0.14 & $333.0633(0.38), 320.0905(-3.87), 318.0736(-7.84), 305.0671(-3.81), 290.0781(-10.62)$ \\
S3 & 13.4 & $\mathrm{C}_{19} \mathrm{H}_{16} \mathrm{NO}_{4}^{+}\left([\mathrm{M}+\mathrm{H}]^{+}\right)$ & 322.1072 & 322.1074 & -0.57 & $307.0864(8.14), 306.0759(-0.6), 292.0948(-6.94), 264.1008(-4.2)$ \\
\hline
\end{tabular}


TABLE 4 | The residue result of sanguinarine and chelerythrine in rat tissues (ng/g).

\begin{tabular}{lccccc}
\hline \multirow{2}{*}{ Tissues } & \multicolumn{2}{c}{ Sanguinarine } & & \multicolumn{2}{c}{ Chelerythrine } \\
\cline { 2 - 3 } \cline { 6 - 6 } & $\mathbf{2 4} \mathbf{h}$ & $\mathbf{4 8} \mathbf{~}$ & & $\mathbf{2 4} \mathbf{~}$ & $\mathbf{4 8 ~} \mathbf{~}$ \\
\hline Liver & 10.38 & 9.8 & & 9.39 & 20.64 \\
Heart & 2.91 & 2.57 & & 2.79 & 3.87 \\
Spleen & 2.01 & 1.91 & & 24.04 & 1.1 \\
Lung & 2.29 & 2.01 & & 1.21 & 1.71 \\
Kidney & 3.77 & 5.65 & & 1.62 & 0.91 \\
\hline
\end{tabular}

respectively. The ion at $\mathrm{m} / z 334$ further lost $\mathrm{CH}_{2} \mathrm{O}$, forming $\mathrm{m} / z$ 304. The ion at $m / z 304$ also lost CO, forming the ion at $m / z 276$. S1 possessed the same retention time, product ions as authentic DHSA. Therefore, $\mathrm{S} 1$ was identified as DHSA.

The retention time of metabolite S2 was $15.3 \mathrm{~min}$, and it showed the $[\mathrm{M}]^{+}$ion at $m / z 348$ (see Table 3), which indicated it may be an oxidative metabolite of sanguinarine. The ion at $\mathrm{m} / z 348$ lost $\mathrm{CH}_{3}$, forming the ion at $\mathrm{m} / z$ 333. It showed that the position of oxidative could not be located on $\mathrm{CH}_{3}$ of $\mathrm{N} 5$. The ion at $\mathrm{m} / z 320$ and $\mathrm{m} / \mathrm{z} 318$ were formed due to loss of $\mathrm{CO}$ and $\mathrm{CH}_{2} \mathrm{O}$ from the ion at $\mathrm{m} / z$ 348, respectively. The ion at $\mathrm{m} / \mathrm{z}$ 320 further lost $\mathrm{CH}_{3}$, forming $\mathrm{m} / z$ 305. The ion at $\mathrm{m} / z 318$ also lost CO forming $\mathrm{m} / \mathrm{z} 290$. Therefore, metabolite S2 could be an oxidative metabolite of sanguinarine located at the positions on the phenyl ring.

The retention time of metabolite S3 was $13.4 \mathrm{~min}$ (see Table 3), and it showed the $[\mathrm{M}+\mathrm{H}]^{+}$ion at $\mathrm{m} / z$ 322, which was 12 Da lower than DHSA, corresponding to the demethylenation metabolite. The product ion at $\mathrm{m} / \mathrm{z} 307$ and $\mathrm{m} / \mathrm{z} 306$ was formed due to loss of $\mathrm{CH}_{3}$ and $\mathrm{CH}_{4}$ from the ion at $m / z 322$, respectively. The ion at $\mathrm{m} / z 322$ lost $\mathrm{CH}_{2} \mathrm{O}$, forming the ion at $\mathrm{m} / z 292$. The ion further saw the loss of CO, forming $\mathrm{m} / z$ 264. Therefore, metabolite S3 could be DHSA O-demethylenation metabolite at the methylenedioxy group.

The HPLC-QqQ MS method was used for further analysis of the rat tissues and for the qualitative determination of sanguinarine and chelerythrine. As shown in Table 4, the distribution of sanguinarine and chelerythrine in rat cecal contents and tissue after intragastric administration of $M$. cordata extracts for 3 weeks. The concentrations of chelerythrine in the liver of $48 \mathrm{~h}$ after dosing and spleen of $24 \mathrm{~h}$ after dosing were 20.64 and $24.04 \mathrm{ng} / \mathrm{g}$, respectively. The concentrations of sanguinarine and chelerythrine in other tissues were $<11 \mathrm{ng} / \mathrm{g}$.

\section{Effects of Inhibitors on Reduction of Chelerythrine Iminium Bond in Rat Liver Cytosol}

Figure 3 showed that all selected inhibitors did not exhibit obvious effects on the DHCHE formation only in the presence of NADPH. However, it was demonstrated that the addition of quercetin, 7-hydroxycoumarin, menadione, and dicoumarol could inhibit the iminium bond reduction of chelerythrine in rat liver cytosol in the presence of NADPH.

\section{Effect on N Q01 Activity in vivo and in vitro Effect on NQO1 Activity in vivo}

The activity of the NQO1 enzyme in the female rats treated with $M$. cordata extracts increased by 64.50 and $52.88 \%$ at 24 and $48 \mathrm{~h}$, respectively, in comparison with control rats (Figure 4A). On the contrary, the activity of the NQO1 enzyme in male rats decreased by 47.55 and $23.47 \%$ at 24 and $48 \mathrm{~h}$, which was statistically significance in contrast to the control (Figure 4B).

\section{The Effect of Sanguinarine and Chelerythrine on NQO1 Activity in vitro}

The effects of chelerythrine and sanguinarine on NQO1 activity are demonstrated in Table 5. The results showed that chelerythrine had a weak impact on NQO1 activity compared to dicoumarol with strong effect on that, and sanguinarine had a statistically significant decline compared to the control, and the $\mathrm{IC}_{50}$ value was $111.57 \mu \mathrm{M}$.

\section{DISCUSSION}

This was the first study that detailed structural elucidations of chelerythrine metabolites in rats in vitro and vivo using an accurate and rapid HPLC/QqTOF-MS method. A total of twelve metabolites of chelerythrine were observed in vitro and in vivo. Among of these metabolites, Ch8 was identified for the first time. Eight metabolites of chelerythrine were found in rat liver S9. In addition to four metabolites (Ch1, Ch2, Ch5, Ch8) observed in rat liver S9, four other metabolites (Ch9-Ch12) were also found in rat feces. Metabolite Ch1 (DHCHE) and Ch2 were the main metabolites in rats in vivo and in vitro, respectively. And $\mathrm{Ch} 2$ was formed by the O-demethylation from Ch1. So, we speculated O-demethylation of DHCHE has an advantage in vitro over in vivo. The difference on the metabolite profiles of chelerythrine between in vitro and in vivo was observed.

According to these results, the possible metabolic pathways of chelerythrine in liver S9 were proposed (Figure 5). The present results indicated that the reduction of the iminium bond of chelerythrine and subsequent O-demethylation were the common metabolic pathway of chelerythrine in rat in vitro and vivo. But the reduction of the iminium bond of chelerythrine and subsequent O-demethylation was the main metabolic pathway of chelerythrine in rat liver S9 while the reduction of the iminium bond of chelerythrine was the main metabolic pathway of chelerythrine in rat in vivo. The Odemethylenated metabolites of DHCHE, O-demethylated and subsequent oxidated metabolites of chelerythrine were also the common metabolic pathways of chelerythrine in rat in vitro and vivo. Additionally, the O-demethylation and subsequent $\mathrm{O}-$ demethylenation of chelerythrine, DHCHE, can be observed in rat liver $\mathrm{S} 9$, and the $\mathrm{O}$-demethylated and subsequent oxidated O-demethylenated of DHCHE were found in rat liver S9. The oxidated metabolite of chelerythrine and DHCHE can be detected in rat in vivo.

No parent drug or metabolites were observed in the plasma of female and male rat at $3 \mathrm{~h}$ following intragastric administration of chelerythrine. Pharmacokinetic study indicated that the $\mathrm{C}_{\max }$, $\mathrm{T}_{\max }$ and $\mathrm{T}_{1 / 2}$ of chelerythrine were $5.06 \mathrm{ng} / \mathrm{ml}, 1.67,2.82 \mathrm{~h}$, 


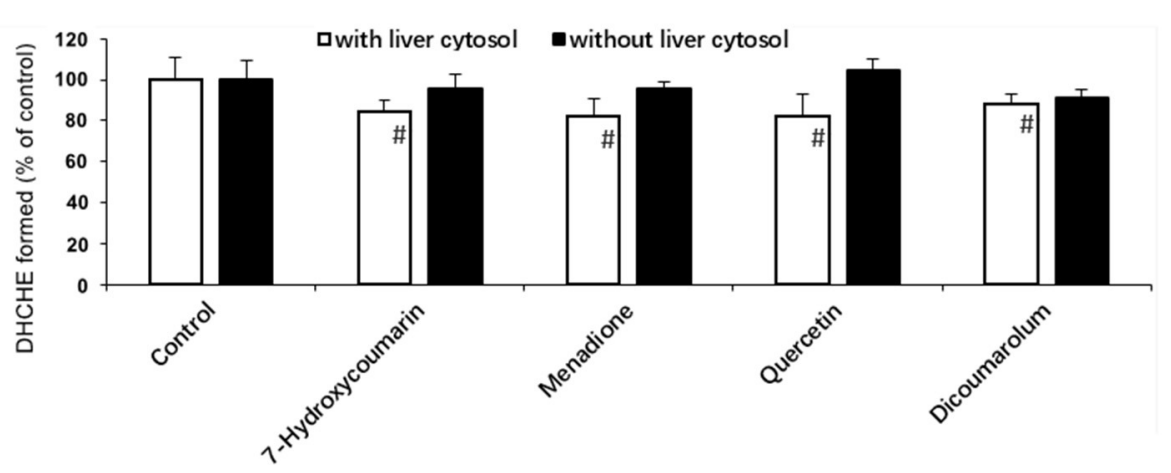

FIGURE 3 | Effect of some inhibitors on the chelerythrine iminium bond reduction to DHCHE by rat liver cytosol. \#p < 0.05, significant when compared to control without inhibitor.
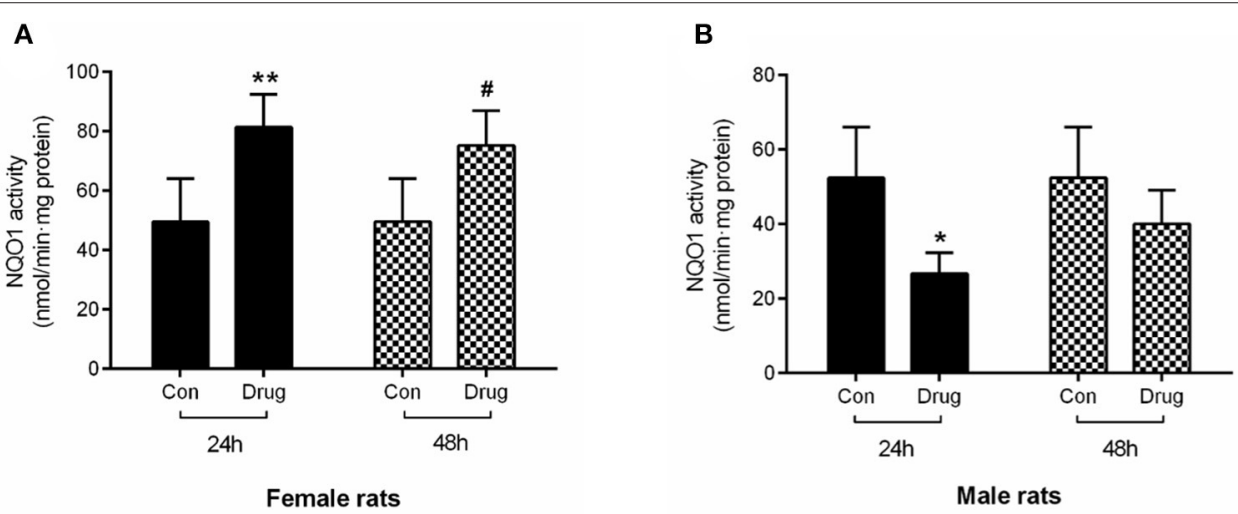

FIGURE 4 | Assessment of in vivo NQO1 activity in female rats (A) and male rats (B) following intragastric administered with $M$. cordata extracts. Con, Control group;

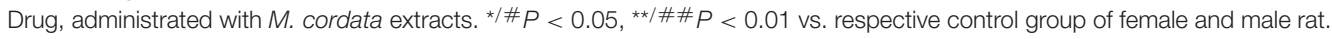

TABLE 5 | Effect of compounds on rat cytosolic NAD(P)H: quinone oxidoreductase activities.

\begin{tabular}{llll}
\hline \multirow{2}{*}{ Compounds } & \multirow{2}{*}{ Concentrtion $(\mu \mathbf{M})$} & \multicolumn{2}{c}{ Rats } \\
\cline { 3 - 4 } & & NQO1 activities & IC $_{50}(\mu \mathbf{M})$ \\
\hline Control & - & $67.14 \pm 4.82$ & - \\
Dicoumarol & 40.00 & $6.18 \pm 0.67^{\star *}$ & $0.008 \pm 0.002$ \\
Chelerythrine & 40.00 & $64.90 \pm 4.24$ & - \\
Sanguinarine & 40.00 & $45.08 \pm 4.34^{\star *}$ & $111.57 \pm 6.17$ \\
\hline
\end{tabular}

$N A D(P) H$, quinone oxidoreductase activity is presented as nanomolars of 2,6dichlorophenolindophenol reduced per minute per milligram of protein. ${ }^{\star \star} P<0.01$.

respectively. No parent drug or metabolites were found in urine of female rats during $0-12 \mathrm{~h}$ after intragastric administration of chelerythrine. But two metabolites (Ch2 and Ch5) identified in liver $\mathrm{S} 9$ were observed in the urine of male rats during $0-12 \mathrm{~h}$ following intragastric administration of chelerythrine, and $\mathrm{Ch} 2$ and Ch5 were not detected in the urine of male rats during the $12-24 \mathrm{~h}$ following intragastric administration of chelerythrine. The result indicated that the absorption and excretion of chelerythrine was fast in rats. Most metabolites were observed in rat feces. Eight and seven chelerythrine metabolites were found in the feces of female and male rats, respectively. The results were consistent with the previously published results (6, 20 ), a majority of the chelerythrine and metabolites were excreted in the feces in $12 \mathrm{~h}$ during the $0-12 \mathrm{~h}$ after drug withdrawal and a small part of the alkaloid was absorbed.

A total of three sanguinarine metabolites were observed following the intragastric administration of $5 \mathrm{mg} / \mathrm{kg}$ (containing about $2 \mathrm{mg} / \mathrm{kg}$ dose of sanguinarine and $1 \mathrm{mg} / \mathrm{kg}$ dose of chelerythrine) $M$. cordata extracts. The main metabolite DHSA was observed in this experiment, consistent with previous reports (13). Except S1, S2, and S3, other reported metabolites were not identified in rats in vivo. We inferred that the reason for this may be related to the dosage and sensitivity of the HPLC/QqTOFMS method.

In China, the extracts of $M$. cordata containing chelerythrine and sanguinarine were approved as the first Traditional Chinese Veterinary Medicine in feed. Products containing M. cordata extract, with a bitter flavor, have been used as a naturally-derived appetizing agent for addition to the feed of production animals including bovine $(21,22)$, poultry $(23,24)$, fish $(25)$, and swine $(26,27)$. With the increasing attention on food safety, it was 


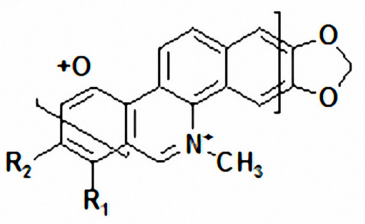

M6 or M11: $\mathrm{R}_{1}=\mathrm{OCH}_{3}, \mathrm{R}_{2}=\mathrm{OH}$; or $\mathrm{R}_{1}=\mathrm{OH}, \mathrm{R}_{2}=\mathrm{OCH}_{3}$<smiles>[R]c1ccc2c3cc(C)cc4c3cc3c(cc-3c-2c[n+]1C)OCO4</smiles>

M5 or M12: $\mathrm{R}_{1}=\mathrm{OCH}_{3}, \mathrm{R}_{2}=\mathrm{OH}$; or $\mathrm{R}_{1}=\mathrm{OH}, \mathrm{R}_{2}=\mathrm{OCH}_{3}$<smiles>[R]c1[R]c2c(cc1)C1=CC(OC)=Cc3cc(O)c(O)cc3[N+](C)=CC=21</smiles>

M7: $\mathrm{R}_{1}=\mathrm{OCH}_{3}, \mathrm{R}_{2}=\mathrm{OH}$; or $\mathrm{R}_{1}=\mathrm{OH}, \mathrm{R}_{2}=\mathrm{OCH}_{3}$<smiles>COc1ccc2c3ccc4cc5c(cc4cc-3[n+](C)c2c1)OCO5</smiles>

O-demethylation<smiles></smiles><smiles>[R]c1ccc2c(c1[R])CN(C)c1c-2cc(OC)c2cc3c(cc12)OCO3</smiles><smiles>[R]c1ccc2c(c1[R])CN(C)c1cc(O)c(O)cc1-2</smiles>

M8

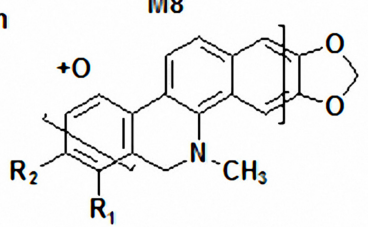

M3: $\mathrm{R}_{1}=\mathrm{OCH}_{3}, \mathrm{R}_{2}=\mathrm{OH}$; or $\mathrm{R}_{1}=\mathrm{OH}, \mathrm{R}_{2}=\mathrm{OCH}_{3}$

M4: $\mathrm{R}_{1}=\mathrm{OCH}_{3}, \mathrm{R}_{\mathbf{2}}=\mathrm{OH}$;

or $\mathrm{R}_{1}=\mathrm{OH}, \mathrm{R}_{2}=\mathrm{OCH}_{3}$

FIGURE 5 | The possible metabolic pathways of chelerythrine in liver S9 and in vivo.

important to study the residue of sanguinarine and chelerythrine in tissues following intragastric administration with $M$. cordata extracts for 3 weeks. After 3 weeks of intragastric administration with M. cordata extracts by using the HPLC/QqTOF-MS method, no sanguinarine and chelerythrine or their metabolites were found in the spleen, lung, kidney, liver or heart. Further, a HPLC-MS/MS was used for imploring the distribution in tissues of sanguinarine and chelerythrine. The concentrations of chelerythrine in the liver $48 \mathrm{~h}$ after dosing and spleen of $24 \mathrm{~h}$ after dosing were 20.64 and $44.04 \mathrm{ng} / \mathrm{ml}$, which were higher than that in others tissues $(<15 \mathrm{ng} / \mathrm{g})$. The concentrations of sanguinarine in the tissues were also $<15 \mathrm{ng} / \mathrm{g}$. The results indicated that sanguinarine and chelerythrine are distributed in different tissues, keeping consistent with previous research (6). Therefore, the active component of photogenic feed additives for livestock may exist in certain tissue residues after feeding.

The chelerythrine transformed into DHCHE by reducing the iminium bond. This may be an important detoxication pathway of chelerythrine in humans and in animals. Previous reports showed that the reduction of sanguinarine iminium bond in cytosolic may lead to carbonyl reductase and/or NQOs (13). But the mechanism of chelerythrine reduction in animals is not clear. In the present study, the inhibitor effects of iminium bond reduction of chelerythrine in rat liver cytosol were investigated. Xanthine oxidase inhibitor 7-hydroxycoumarin, NQO1 inhibitor dicoumarol, NQO2 and carbonyl reductase inhibitor quercetin and menadionea specific substrate of carbonyl reductase and NQO2 had significant effect on DHCHE formation in rat liver cytosol in the presence of NADPH. The results that indicated XO, NQO1, NQO2, and carbonyl reductase are involved in chelerythrine reduction. We also propose the mechanism of chelerythrine reduction in the rat liver cytosol as shown in Figure 6. The difference of reduction metabolism mechanism between sanguinarine and chelerythrine may be related to their structure. 
<smiles>COc1ccc2c3c(c(OC)c(OC)c2c1)-c1ccc2cc4c(cc2c1N(C)C3)OCO4</smiles><smiles>COc1ccc2c(c1OC)CN(C)c1c-2ccc2cc3c(cc12)OCO3</smiles>

FIGURE 6 | The mechanism of chelerythrine reduction in the rat liver cytosol.

Sanguinarine and chelerythrine are active substances in $M$. cordata extracts. But the effects of sanguinarine and chelerythrine on drug-metabolizing enzymes in vivo have not been reported. In this study, the impact of $M$. cordata extracts on the activity of NQO1 in male and female rats were investigated. The results indicated that the treatment of rats with $M$. cordata extracts induced the activity of NQO1 in female rats, but inhibition activity in male rats. Clinical and experimental observations show that the female's response to dietary sodium chloride (salt sensitivity) may be different from that of the male due to the intermediate effects of the sex hormone patterns and gender-related genetic factors (19). Therefore, we suspected that the gender difference in drug-metabolizing enzymes between sanguinarine and chelerythrine might be related to the difference in enzyme activities that were regulated by sex hormones. Further, we investigated the impact of sanguinarine and chelerythrine on NQO1 activity. The result indicated chelerythrine had a weak impact on NQO1 activity, but sanguinarine inhibited NQO1 activity. It provides more comprehensive information in the chelerythrine metabolism and mechanism, and will be helpful to application of M. cordata extracts in veterinary and human medicine.

\section{CONCLUSIONS}

The current study investigated comprehensively the biotransformation of chelerythrine in the urine, feces, and plasma of rats following intragastric administration of chelerythrine and in vitro in rat. The tissue distribution of sanguinarine and chelerythrine was explored further after intragastric administration of $M$. cordata extracts for 3 weeks. The effects of cytosolic reductase inhibitors on chelerythrine reduction and the impact of chelerythrine and sanguinarine on the activity of
NQO1 in vitro and in vivo were also examined in this study. These findings provide a reference for the clinical veterinary application and food safety evaluation of $M$. cordata extracts.

\section{DATA AVAILABILITY STATEMENT}

The original contributions presented in the study are included in the article/Supplementary Material, further inquiries can be directed to the corresponding author/s.

\section{ETHICS STATEMENT}

The animal study was reviewed and approved by the Institutional animal care and use committee of Hunan Research Center.

\section{AUTHOR CONTRIBUTIONS}

Z-YL and Y-JH participated in creating the experimental design. Y-JH and Z-YZ performed the handling of animals and sample collection. C-YH, Y-JH, and Y-SL analyzed the data and discussed the obtained results. C-YH, Y-JH, and Z-YL wrote manuscript. All authors contributed to the article and approved the submitted version.

\section{FUNDING}

This work was supported by National Key R\&D Program of Intergovernmental Key Projects of China (Grant No: 2018YFE0101700).

\section{SUPPLEMENTARY MATERIAL}

The Supplementary Material for this article can be found online at: https://www.frontiersin.org/articles/10.3389/fvets. 2021.659771/full\#supplementary-material 


\section{REFERENCES}

1. Vienna CF, Graz RB, Hohenheim RC, Milano DT, Trieste AT, Wien ZE, et al. Study on the assessment of plants/herbs, plant/herb extracts and their naturally or synthetically produced components as 'additives' for use in animal production. EFSA Support Publ. (2007) 4:070828. doi: 10.2903/sp.efsa.2007.ZN-001

2. Stiborova M, Vostalova J, Zdarilova A, Ulrichova J, Hudecek J, Tschirner $\mathrm{K}$, et al. Macleaya cordata extract and Sangrovit genotoxicity. Assessment in vivo. Biomed Pap Med Fac Univ Palacky Olomouc Czech Repub. (2008) 152:35-9. doi: 10.5507/bp.2008.005

3. Lin L, Liu YC, Huang JL, Liu XB, Qing ZX, Zeng JG, et al. Medicinal plants of the genus Macleaya (Macleaya cordata, Macleaya microcarpa): a review of their phytochemistry, pharmacology, and toxicology. Phytother Res. (2018) 32:19-48. doi: 10.1002/ptr.5952

4. Paraskevas S. Randomized controlled clinical trials on agents used for chemical plaque control. Int J Dent Hyg. (2010) 3:162-78. doi: 10.1111 / j.1601-5037.2005.00145.x

5. Vichkanova SA, Tolkachev ON, Martynova RG, Arzamastsev EV. Sanguiritrin, a new antimicrobial drug. Pharm Chem J. (1982) 16:925-9. doi: 10.1007/BF00767855

6. Kosina P, Walterová D, Ulrichová J, Lichnovský V, Stiborová M, Rýdlová $\mathrm{H}$, et al. Sanguinarine and chelerythrine: assessment of safety on pigs in ninety days feeding experiment. Food Chem Toxicol. (2004) 42:8591. doi: 10.1016/j.fct.2003.08.007

7. Kosina P, Vacek J, Papoušková B, Stiborová M, Stýskala J, Cankar P, et al. Identification of benzo[c]phenanthridine metabolites in human hepatocytes by liquid chromatography with electrospray ion-trap and quadrupole timeof-flight mass spectrometry. J Chromatogr B Analyt Technol Biomed Life Sci. (2011) 879:1077-85. doi: 10.1016/j.jchromb.2011.03.023

8. Sandor R, Midlik A, Sebrlova K, Dovrtelova G, Noskova K, Jurica J, et al. Identification of metabolites of selected benzophenanthridine alkaloids and their toxicity evaluation. J Pharm Biomed Anal. (2016) 121:17480. doi: 10.1016/j.jpba.2016.01.024

9. Vacek J, Papoušková $\mathrm{B}$, Kosina $\mathrm{P}$, Galandáková A, Ulrichová J. Mass spectrometric investigation of chelerythrine and dihydrochelerythrine biotransformation patterns in human hepatocytes. J Chromatogr B Analyt Technol Biomed Life Sci. (2013) 941:17-24. doi: 10.1016/j.jchromb.2013.09.037

10. Weiss D, Baumert A, Vogel M, Roos W. Sanguinarine reductase, a key enzyme of benzophenanthridine detoxification. Plant Cell Environ. (2006) 29:291-302. doi: 10.1111/j.1365-3040.2005.01421.x

11. Janovská M, Kubala M, Šimánek V, Ulrichová J. Fluorescence of sanguinarine: fundamental characteristics and analysis of interconversion between various forms. Anal Bioanal Chem. (2009) 395:235-40. doi: 10.1007/s00216-009-2903-9

12. Matkar SS, Wrischnik LA, Hellmann-Blumberg U. Production of hydrogen peroxide and redox cycling can explain how sanguinarine and chelerythrine induce rapid apoptosis. Arch Biochem Biophys. (2008) 477:43-52. doi: 10.1016/j.abb.2008.05.019

13. Wu Y, Liu Z-Y, Cao Y, Chen X-J, Zeng J-G, Sun Z-L. Reductive metabolism of the sanguinarine iminium bond by rat liver preparations. Pharmacol Rep. (2013) 65:1391-400. doi: 10.1016/S1734-1140(13)71498-1

14. Zhang D-S, Liu Z-Y, Li YJ, Sun Z-L. NQO1 involves in the imine bond reduction of sanguinarine and recombinant adeno-associated virus mediated NQO1 overexpression decreases sanguinarine-induced cytotoxicity in rat BRL cells. Toxicol Lett. (2014) 225:119-29. doi: 10.1016/j.toxlet.2013.11.028

15. Psotová J, Klejdus B, Vecera R, Kosina P, Kubán V, Vicar J, et al. A liquid chromatographic-mass spectrometric evidence of dihydrosanguinarine as a first metabolite of sanguinarine transformation in rat. J Chromatogr B Analyt Technol Biomed Life Sci. (2006) 830:165-72. doi: 10.1016/j.jchromb.2005.10.030

16. Vrublova E, Vostalova J, Vecera R, Klejdus B, Stejskal D, Kosina P, et al. The toxicity and pharmacokinetics of dihydrosanguinarine in rat: a pilot study. Food Chem Toxicol. (2008) 46:2546-53. doi: 10.1016/j.fct.2008. 04.013

17. Zhang H-H, Wu Y, Sun Z-L, Liu Z-Y. Identification of sanguinarine metabolites in pig liver preparations by accurate mass measurements using electrospray ionization hybrid ion trap/time-of-flight mass spectrometry. Rapid Commun Mass Spectrom. (2013) 27:979-84. doi: 10.1002/rcm.6538

18. Huang Y-J, Xiao S, Sun Z-L, Zeng J-G, Liu Y-S, Liu Z-Y. Identification of allocryptopine and protopine metabolites in rat liver $S 9$ by high-performance liquid chromatography/quadrupole-time-of-flight mass spectrometry. Rapid Commun Mass Spectrom. (2016) 30:1549-59. doi: 10.1002/rcm.7586

19. Huang Y-J, Cheng P, Zhang Z-Y, Tian S-J, Sun Z-L, Zeng J-G, et al. Biotransformation and tissue distribution of protopine and allocryptopine and effects of Plume Poppy Total Alkaloid on liver drug-metabolizing enzymes. Sci Rep. (2018) 8:1-3. doi: 10.1038/s41598-017-18816-7

20. Zdarilova A, Vrublova E, Vostalova J, Klejdus B, Stejskal D, Proskova J, et al. Natural feed additive of Macleaya cordata: safety assessment in rats a 90-day feeding experiment. Food Chem Toxicol. (2008) 46:37216. doi: 10.1016/j.fct.2008.09.054

21. Aguilar-Hernández JA, Urías-Estrada JD, López-Soto MA, Barreras A, Plascencia A, Montaño $\mathrm{M}$, et al. Evaluation of isoquinoline alkaloid supplementation levels on ruminal fermentation, characteristics of digestion, and microbial protein synthesis in steers fed a high-energy diet. J Anim Sci. (2016) 94:267-74. doi: 10.2527/jas.2015-9376

22. Estrada-Angulo A, Aguilar-Hernández A, Osuna-Pérez M, Núñez-Benítez VH, Castro-Pérez BI, Silva-Hidalgo G, et al. Influence of quaternary benzophenantridine and protopine alkaloids on growth performance, dietary energy, carcass traits, visceral mass, and rumen health in finishing ewes under conditions of severe temperature-humidity index. Asian Aust J Anim Sci. (2016) 29:652-8. doi: 10.5713/ajas.15.0300

23. Lee KW, Kim JS, Oh ST, Kang CW, An BK. Effects of dietary sanguinarine on growth performance, relative organ weight, cecal microflora, serum cholesterol level and meat quality in broiler chickens. J Poult Sci. (2015) 52:15-22. doi: 10.2141/jpsa.0140073

24. Matulka RA, von Alvensleben S, Morlacchini M. Tolerance and residue study for standardized Macleaya cordata extract added to chicken feed. Int J Poult Sci. (2014) 13:368. doi: 10.3923/ijps.2014.368.373

25. Rawling M, Merrifield DL, Davies SJ. Preliminary assessment of dietary supplementation of Sangrovit on red tilapia (Oreochromis niloticus) growth performance and health. Aquaculture. (2009) 294:118-22. doi: 10.1016/j.aquaculture.2009.05.005

26. Artuso-Ponte V, Moeller S, Rajala-Schultz P, Medardus JJ, Munyalo J, Lim K, et al. Supplementation with quaternary benzo(c)phenanthridine alkaloids decreased salivary cortisol and salmonella shedding in pigs after transportation to the slaughterhouse. Foodb Pathog Dis. (2015) 12:8917. doi: 10.1089/fpd.2015.2009

27. Kantas D, Papatsiros VG, Tassis PD, Athanasiou LV, Tzika ED. The effect of a natural feed additive (Macleaya cordata), containing sanguinarine, on the performance and health status of weaning pigs. Anim Sci J. (2015) 86:92-8. doi: 10.1111/asj.12240

Conflict of Interest: Y-JH was employed by company Hunan Prima Drug Research Center.

The remaining authors declare that the research was conducted in the absence of any commercial or financial relationships that could be construed as a potential conflict of interest.

Copyright (C) 2021 Huang, Huang, Zhang, Liu and Liu. This is an open-access article distributed under the terms of the Creative Commons Attribution License (CC BY). The use, distribution or reproduction in other forums is permitted, provided the original author(s) and the copyright owner(s) are credited and that the original publication in this journal is cited, in accordance with accepted academic practice. No use, distribution or reproduction is permitted which does not comply with these terms. 